\title{
Generalizing of Finite Difference Method for Certain Fractional Order Parabolic PDE's
}

\author{
Madeha Shaltagh Yousif \\ Madehashltagh@gmail.com \\ Eman Hassan Ouda \\ emanhasan1966@yahoo.com
}

\author{
Ahmed Mohamed Shukur \\ ahmhald4@gmail.com \\ Raghad Kadhim Salih \\ raghadkadhimsa@gmail.com
}

\section{Part of Applied Mathematics, Department of Applied Science, University of Technology, Baghdad, Iraq.}

Recived : $3 \backslash 5 \backslash 2018$

Available online : $\quad \mathbf{5 / 8 / 2 0 1 8}$

DOI: 10.29304/jqcm.2018.10.3.404

\begin{abstract}
Space-time fractional differential equation with integral term (S-TFDE) has been considered.

The finite difference method (implicit and explicit) combined with the trapezoidal integration formula has been used to

find special formula to solve this equation. The stability and convergence have been discussed. The effect of adding an

integral term to the common classical equation has been considered. Graphical representation of the calculate solutions

(obtained by the explicit and the implicit methods) for three numerical examples with their exact solution, are considered. All the calculations and graphs are designed with the help of MATLAB.
\end{abstract}

Keywords: fractional order PDE, fractional itegro-differential equation, fractional Parabolic

Mathematics Subject Classification: ASMC-204. 


\section{1 - Introduction}

Fractional order differential equations have excited, in recent years, a considerable interest both in mathematics and in applications. They were used in modeling of many physical, chemical processes and engineering. A physical mathematical approach to anomalous partial differential equations (PDE), may be based on generalized (PDE) containing derivatives of fractional order in one only (space or time), or in together space and time. It is well known that the differential equations represent local interactions in the mathematical models, while the representation of integral equation represent the global interactions of the phenomenon, see for examples [1, 2,3, 4and 5]. Many researchers used different methods to solve different models of the fractional order equations. Meerschaert and Tadiran [6] used the finite difference method to solve the space-fractional advection dispersion. R. Gorenflo, F. Mainardi [7] used Laplace transform to solve Fractional Order linear Integral and Differential Equations. J.P. Roop, [8], considered boundary value problems in R2 with the finite element method. Our main objective is studying the following fractional order equation:

$$
\frac{\partial^{\alpha} u(x, t)}{\partial t^{\alpha}}=\frac{\partial^{\beta} u(x, t)}{\partial x^{\beta}}+\int_{o}^{t} u(x, s) d s+q(x, t)
$$

where: $0<\alpha \leq 1 ; 1<\beta \leq 2 ; 0 \leq \mathrm{x} \leq 1 ; 0 \leq \mathrm{t} \leq \mathrm{T}$ with initial and boundary conditions given respectively:

$$
\begin{aligned}
& \mathrm{u}(\mathrm{x}, 0)=\mathrm{f}(\mathrm{x}) \quad 0 \leq \mathrm{x} \leq 1 \\
& \mathrm{u}(0, \mathrm{t})=\mathrm{u}(1, \mathrm{t})=0
\end{aligned}
$$

Corresponding to the classical integro-differential parabolic form:

$$
\frac{\partial u(x, t)}{\partial t}=\frac{\partial^{2} u(x, t)}{\partial x^{2}}+\int_{o}^{t} u(x, s) d s+q(x, t)
$$

Considered by [9]. The effect of the integral term will be studied in both, implicit and explicit methods, when solving the class of initial boundary value space-time fractional equation (1).

\section{2-material and method}

The numerical treatment of fractional order partial differential equations has its importance because the limited use of the analytical methods In many cases there is no analytical treatment for different reasons concerning the domain under consideration or the regularity of the boundary or even the equation itself. Many authors have considered the numerical treatment of space or time fractional partial differential equations. Zhuang and Liu [10], implicit difference approximation for the time fractional diffusion equation has been considered.
Also they analyzed the stability and convergence. S. Shen and F. Liu [11] proposed an explicit difference approximation for the space fractional diffusion equation and gave an error analysis. M. Meerschaert and C. Tadjeran [12] proposed finite difference approximation for fractional advection dispersion flow equations. Mainardi [13] the fundamental solution of the space-time fractional diffusion equation was discussed, he deals with the Cauchy problem for the space-time fractional diffusion equation. Gorenflo [14], a discrete random walk model for space-time fractional diffusion was proposed .Diego A. Murio[15],developed an implicit unconditionally stable finite difference scheme to solve the linear one-dimensional diffusion equation with fractional time derivatives. F. Liu, S. Shen, V. Anh and I. Turner[18], an explicit finite difference scheme for time fractional differential equation is presented. Discrete models of a non-Markovian random walk are generated for simulating random processes whose spatial probability density evolves in time according to this fractional diffusion equation. In this work proposed fractional order implicit and explicit finite difference approximation for space-time fractional heat equation with integral term (1), (S-T FDE). Riemann-Liouvill fractional derivative of order $1<\beta \leq 2$, Caputo fractional derivative of order $0<\alpha \leq 1$, are using, trapezoidal method has been used to approximate the integral term, studying of stability and convergence of both methods, that will be given through studying of different examples.

\section{3-Theory and basic definitions}

Riemann, Caputo and Grunewald, fractional integral and fractional derivatives that be used for approximating derivatives, will be given. Also, trapezoidal rule will be used to approximate integral term, For more detail, see $[15,16,17]$.

\section{3-1 Riemann-Liouville}

fractional Integral of order $\beta>0$ given by the form [1-18],

$$
\begin{aligned}
& J_{t}^{\beta} f(t)=\left\{\begin{array}{c}
\frac{1}{\Gamma(\beta)} \int_{0}^{t}(t-s)^{\beta-1} f(s) d s \\
J_{t}^{0}=I
\end{array}\right. \\
& \text { (2) } J_{t}^{\beta} J_{t}^{\alpha}=J_{t}^{\alpha} J_{t}^{\beta}=J_{t}^{\alpha+\beta} \text { Where } \alpha \geq 0, \beta \geq 0
\end{aligned}
$$




\section{3-2 Riemann-Liouville fractional derivative of order}

let $\mathrm{m}$ denotes a positive integer such that $\mathrm{m}-1<\beta \leq \mathrm{m}$, then fractional order derivative Riemann-Liouville of order $\beta$ will be given by the form:

$$
\begin{aligned}
& { }_{t}^{R}{ }_{t}^{\beta}=D_{t}^{m} J_{t}^{m-\beta} f(t) \quad \text { This mean } \\
& { }^{R}{ }_{t}^{\beta} f(t)= \\
& \left\{\begin{array}{l}
\frac{d^{m}}{d t^{m}}\left[\frac{1}{\Gamma(m-\beta)} \int_{0}^{t}(t-s)^{m-\beta-1} f(s) d s\right] m-1<\beta<m \\
\frac{d^{m}}{d t^{m}} f(t)
\end{array} \quad \beta=m\right. \\
& D_{t}^{m} J_{t}^{\beta}=I, \quad \beta>0 \quad \text { where } D_{t}^{0}=I \quad
\end{aligned}
$$

\section{3-3 Caputo fractional derivate}

Let $\mathrm{m}$ denotes a positive integerm- $1<\alpha \leq \mathrm{m}$, then the Caputo's fractional derivative of order $\alpha$ given by:

$$
\begin{aligned}
& { }^{c}{ }_{t}^{\alpha}=J_{t}^{m-\alpha} D_{t}^{m} f(t) \quad \text { This mean: } \\
& { }^{c}{ }^{\alpha} f(t)= \\
& \left\{\begin{array}{lr}
{\left[\frac{1}{\Gamma(m-\alpha)} \int_{t}^{t}(t-s)^{m-\alpha-1} f^{(m)}(s) d s\right] m-1<\alpha<m} \\
\frac{d^{m}}{d t^{m}} f(t) & \alpha=m
\end{array}\right.
\end{aligned}
$$

\section{Some properties of fractional derivatives:}

$D_{t}^{\alpha} t^{k}=\left\{\begin{array}{lr}\frac{\Gamma(k+1)}{\Gamma(k-\alpha+1)} t^{k-\alpha} & k \geq \alpha \\ 0 & k<\alpha\end{array}\right.$

Since $e^{a t}=\sum_{k=0}^{\infty} \frac{(a t)^{k}}{\Gamma(k+1)}$ and using first property,

with the linearity of operator $D_{t}^{\alpha}$, then

$D_{t}^{\alpha} e^{a t}=a^{\alpha} \sum_{k=0}^{\infty} \frac{(a t)^{k-\alpha}}{\Gamma(k-\alpha+1)}$, and since all terms of these infinite series equal zero if $(\mathrm{k}<\alpha)$, let $\mathrm{s}=\mathrm{k}-\alpha$ then:

$$
D_{t}^{\alpha} e^{-t}=a^{\alpha} \sum_{s=0}^{\infty} \frac{(a t)^{s}}{\Gamma(s+1)}=a^{\alpha} e^{-t}=a^{\alpha} E_{\alpha}^{a t}=e^{i \pi \alpha} E_{\alpha}^{a t}
$$

where $\mathrm{a}=-1$; for $\mathrm{a}=1$ then $D_{t}^{\alpha} e^{t}=e^{t}$ by the same way $D_{t}^{\alpha} \sin (b t)=(b)^{\alpha} \sin \left(b t+\frac{\alpha \pi}{2}\right)$.where $\mathrm{b}$ is constant.

\section{3-4 Grünwald formula}

The fractional derivative can be written with the help of Grünwald formula as:

$$
\frac{d^{\beta}}{d x^{\beta}} f(x)=\lim _{m \rightarrow \infty} \frac{1}{h^{\beta}} \sum_{k=o}^{m} g_{k} f(x-k h)
$$

Where the normalized Grünwald's weights function will be defined as:

$$
g_{0}=1 ; g_{1}=-\beta ; g_{k}=\frac{\beta(\beta-1)(\beta-2) \cdots(\beta-k+1)}{k !} \text {. }
$$

Note: that these normalized weights depend only on the order $\beta$ and the index $\mathbf{k}$.

M.M. Meerschaert, J. Mortensen and H.P, Scheffler, [18] developed an extension of the Grünwald formula for vector fractional derivatives. And use this result for numerical solution of fractional partial differential equations where the space variable is a vector.

\section{3-5 The trapezoidal rule}

To approximate the integral term appear in equation (1), trapezoidal rule will be used as.

$$
\int_{a}^{b} f(x) d x \cong T(f, a, b)+E_{T}(f, a, b),
$$

Where, $T(f, a, b)=\frac{(b-a)}{2}(f(a)+f(b))$

$$
E_{T}(f, a, b)=\frac{(b-a)^{3} f^{(2)}(\xi)}{12}, \quad \xi \in(a, b)
$$

To preserve the accuracy of the overall approximation of the finite difference representation of equations (1) we use the composite form of the trapezoidal rule, suppose that the interval $[a, b]$ is subdivided into $\mathrm{m}$ subintervals $\left[x_{i-1}, x_{i}\right], \quad i=1,2, \cdots, m$ of width $h=\frac{b-a}{m}$; so that $x_{i}=a+i h$, the composite rule takes the form $\int_{a}^{b} f(x) d x \cong T(f, h)+E_{T}(f, h)$

Where:

$T(f, h)=\frac{h}{2}(f(a)+f(b))+h \sum_{i=1}^{m-1} f\left(x_{i}\right)$,

$E_{T}(f, h)=O\left(h^{2}\right)=-\frac{(b-a) f^{(2)}(\xi)}{12} h^{2}$, Now for $\mathrm{u}(\mathrm{x}, \mathrm{t}) ; \mathrm{t} \in[0, \mathrm{~T}]$, divide $[0, \mathrm{~T}]$, into $\mathrm{m}$ subintervals $\left[t_{k-1}, t_{k}\right]$ of width $\tau=\frac{T-0}{n}$, let $\mathrm{t}_{\mathrm{k}}=\mathrm{k} \tau$ 
where $\quad(\mathrm{k}=0,1,2, \ldots, \mathrm{n}), \quad \mathrm{n} \in \mathrm{N}^{+}, \quad$ then
$\int_{0}^{T} u(x, s) d s \cong \frac{\tau}{2}[u(x, 0)+u(x, T)]+\tau \sum_{k=1}^{n-1} u\left(x, t_{k}\right)+O\left(\tau^{2}\right)$ (9)

\section{4- Numerical Solution:}

Consider equation (1) with the initial and boundary conditions, where the time fractional derivative is understood in the sense of Caputo and the space derivative appearing in the right hand side is understood in the sense of Riemann-Liouville.

Let $u_{i}^{k}=u\left(x_{i}, t_{k}\right)$ for all $\mathrm{i}, \mathrm{k}$, let $x_{i}=i h, h=\frac{1}{m}$ and

$t_{k}=k \tau ; \tau=\frac{T}{n}$ where $i=0,1,2, \cdots, m$;

$k=0,1,2, \cdots, n$.

Replace the terms in equation (1) by its approximation to obtain an algebraic relations which are satisfied some accuracy at each point. in these algebraic equations, The approximation will classify as explicit or implicit according to the appearance of the unknowns in each equation. The algebraic system or the approximation is termed explicit, if the system can be arranged, where that every equation contains only one unknown otherwise it is implicit.

Let $\mathrm{u}_{\mathrm{i}} \mathrm{k}^{\mathrm{k}}=u\left(x_{i}, t_{k}\right) ;(\mathrm{i}=0,1, \ldots, \mathrm{m} ; \mathrm{k}=0,1, \ldots, \mathrm{n})$ be the exact solution of equation (1) at the mesh points $\left(\mathrm{x}_{\mathrm{i}}, \mathrm{t}_{\mathrm{k}}\right)$.

Let $\mathrm{U}_{\mathrm{i}}^{\mathrm{k}}$ be the numerical approximation to exact solution at the same mesh points $\left(x_{i}, t_{k}\right)$.

\section{4-1 Explicit Method}

Explicit finite difference method will be used in this section, to find approximation-solution of equation (1).

Using the following approximations:

The approximation of Caputo's fractional derivative of order $\alpha$ given as:

$$
\begin{aligned}
& \frac{\partial^{\alpha} u\left(x_{i}, t_{k+1}\right)}{\partial t^{\alpha}}=\frac{1}{\Gamma(1-\alpha)} \\
& \sum_{j=0}^{k} \frac{u\left(x_{i}, t_{j+1}\right)-u\left(x_{i}, t_{j}\right)}{\tau} \int_{j \tau}^{(j+1) \tau} \frac{d z}{\left(t_{k+1}-z\right)^{\alpha}}+o(\tau)
\end{aligned}
$$

Let $\mathrm{s}=\left(t_{k+1}-z\right)$ then equation (10) becomes:

$$
\begin{aligned}
& \frac{\partial^{\alpha} u\left(x_{i}, t_{k+1}\right)}{\partial t^{\alpha}} \cong \frac{\tau}{\Gamma(1-\alpha)} \\
& \sum_{j=0}^{k}\left[u\left(x_{i}, t_{k-j+1}\right)-u\left(x_{i}, t_{k-j}\right)\right] \int_{j \tau}^{(j+1) \tau} \frac{d z}{s^{\alpha}}+o(\tau)
\end{aligned}
$$

$$
\begin{aligned}
& \frac{\partial^{\alpha} u\left(x_{i}, t_{k+1}\right)}{\partial t^{\alpha}} \cong \frac{\tau^{-\alpha}}{\Gamma(2-\alpha)} \\
& \sum_{j=0}^{k}\left[u\left(x_{i}, t_{k-j+1}\right)-u\left(x_{i}, t_{k-j}\right)\right]\left[(j+1)^{\alpha}-(j)^{1-\alpha}\right]+o(\tau)
\end{aligned}
$$

Let $b_{j}=\left[(j+1)^{\alpha}-(j)^{1-\alpha}\right] ; \mathrm{j}=0,1,2, \ldots$

$$
\begin{aligned}
& \frac{\partial^{\alpha} u\left(x_{i}, t_{k+1}\right)}{\partial t^{\alpha}} \cong \frac{\tau^{-\alpha}}{\Gamma(2-\alpha)} \\
& \sum_{j=0}^{k} b_{j}\left[u\left(x_{i}, t_{k-j+1}\right)-u\left(x_{i}, t_{k-j}\right)\right]+o(\tau)
\end{aligned} ; 0<\alpha \leq 1
$$

Now. Grünwald formula used to approximate Riemann-Liouville fractional derivative of order $1 \leq$ $\beta \leq 2$ :

$$
\begin{aligned}
& \frac{\partial^{\beta} u\left(x_{i}, t_{k}\right)}{\partial x^{\beta}}=D_{x}^{\beta} u\left(x_{i}, t_{k}\right) \\
& =\frac{1}{h^{\beta}} \sum_{j=0}^{i+1} g_{j} u\left(x_{j}-(i-1) h, t_{k}\right)+O(\tau+h)
\end{aligned}
$$

Where for $\mathrm{i}=0,1,2, \ldots ; 0<\beta \leq 2$;

$$
g_{0}=1 ; g_{1}=-\beta ; g_{j}=(-1)^{j} \frac{\beta(\beta-1)(\beta-2) \ldots(\beta-j+1)}{j !}
$$

Let $x_{i}=i h, h=\frac{1}{m}$ and $t_{k}=k \tau ; \tau=\frac{T}{n}$

Where $i=0,1,2, \cdots, m ; k=0,1,2, \cdots, n$.

$$
\omega=\tau^{\alpha} \Gamma(2-\alpha) ; r=\frac{\omega}{h^{\beta}} ; c=\frac{\tau \omega}{2}
$$

Now putting equations $(9,14$ and 15$)$ in equation (1), with some simple algebraic operations, the general system of equations has been written as:

$$
\begin{aligned}
& \sum_{j=0}^{k} b_{j}\left(u_{i}^{k-j+1}-u_{i}^{k-j}\right)=r \sum_{j=0}^{k} g_{j} u_{i-j+1}^{k+1}+ \\
& +\sum_{j=0}^{k} c\left(u_{i}^{k-j+1}-u_{i}^{k-j}\right)+q_{i}^{k}+o(\tau+h)
\end{aligned}
$$

This system of equations (17) has the forms at $(\mathrm{k}=0$ and $\mathrm{k} \geq 1$ ) respectively:

$$
u_{i}^{1}=(1-\beta r) u_{1}^{0}+r \sum_{\substack{j=0 \\ j \neq 1}}^{i+1} g_{1} u_{i-j+1}^{0} \quad \text { For } \mathrm{k}=0
$$

$$
\begin{gathered}
u_{i}^{k+1}=\left(1+c-\beta r-b_{1}\right) u_{i}^{k}+r \sum_{\substack{j=0 \\
j \neq 1}}^{i+1} g_{j} u_{i-j+1}^{k+1}+ \\
\left(1-b_{1}\right) u_{1}^{0}+\sum_{j=1}^{k-1}\left(2 c+b_{j}-b_{j+1}\right) u_{i}^{k-1}+\omega q_{i}^{k}
\end{gathered}
$$


By using matrix formula this system will be written as: $\quad \mathrm{U}^{\mathrm{k}+1}=\mathrm{A} \mathrm{U}^{\mathrm{k}}$ where

$$
\left\{\begin{aligned}
U^{1}=A U^{0} & \\
U^{k+1}= & A U^{k}+\left(c+b_{k}\right) U^{0}+\omega G_{i}^{k}+ \\
& +\sum_{j=1}^{k-1}\left(2 c+b_{j}-b_{j+1}\right) u_{i}^{k-1}
\end{aligned}\right\}
$$

Where $A=\left[\mathrm{A}_{\mathrm{ij}}\right]$ is the matrix of coefficient, has form:

$$
A_{i j}=\left\{\begin{array}{lr}
r & j=i+1 \\
1-\beta r & j=i=1 \\
1+c-\beta r-b_{1} & j=i=2,3, \ldots, m \\
r g_{2} & j=i-1 \\
r g_{i-j+1} & j \leq i-2 \\
0 & \text { otherwise }
\end{array}\right\}
$$

$$
\left.\begin{array}{c}
U_{k}=\left[U_{1}^{k}, U_{2}^{k}, \ldots, U_{m-1}^{k}\right]^{T} ; \\
\text { Where } f=\left[f\left(x_{1}\right), f\left(x_{2}\right), f\left(x_{3}\right), \ldots, f\left(x_{m-1}\right)\right]^{T} \\
Q_{k}=\left[q_{1}^{k}, q_{2}^{k}, \ldots, q_{m-1}^{k}\right]^{T} ;
\end{array}\right\}
$$

\section{4-2 Implicit Method:}

By using the same approximation in section 4-1 to approximate the fractional derivatives in implicit formula one will get:

$$
\begin{aligned}
& \frac{\partial^{\alpha} u\left(x_{i}, t_{k+1}\right)}{\partial t^{\alpha}}=\frac{1}{\Gamma(1-\alpha)} \\
& \sum_{j=0}^{k} \frac{u\left(x_{i}, t_{j+1}\right)-u\left(x_{i}, t_{j}\right)}{\tau} \int_{j \tau}^{(j+1) \tau} \frac{d z}{\left(t t_{k-1}-z\right)^{\alpha}}+o(\tau)
\end{aligned}
$$

Let $\mathrm{s}=\left(t_{k+1}-z\right)$ we have:

$$
\begin{aligned}
& \frac{\partial^{\alpha} u\left(x_{i}, t_{k+1}\right)}{\partial t^{\alpha}} \cong \frac{\tau}{\Gamma(1-\alpha)} \\
& \sum_{j=0}^{k}\left[u\left(x_{i}, t_{k-j+1}\right)-u\left(x_{i}, t_{k-j}\right)\right] \int_{j \tau}^{(j+1) \tau} \frac{d z}{s^{\alpha}}+o(\tau)
\end{aligned}
$$

$$
\begin{aligned}
& \frac{\partial^{\alpha} u\left(x_{i}, t_{k+1}\right)}{\partial t^{\alpha}} \cong \frac{\tau^{-\alpha}}{\Gamma(2-\alpha)} \\
& \sum_{j=0}^{k}\left[u\left(x_{i}, t_{k-j+1}\right)-u\left(x_{i}, t_{k-j}\right)\right]\left[(j+1)^{\alpha}-(j)^{1-\alpha}\right]+o(\tau)
\end{aligned}
$$

Let $b_{j}=\left[(j+1)^{\alpha}-(j)^{1-\alpha}\right] ; \mathrm{j}=0,1,2, \ldots$

$$
\begin{aligned}
& \frac{\partial^{\alpha} u\left(x_{i}, t_{k+1}\right)}{\partial t^{\alpha}} \cong \frac{\tau^{-\alpha}}{\Gamma(2-\alpha)} \\
& \sum_{j=0}^{k} b_{j}\left[u\left(x_{i}, t_{k-j+1}\right)-u\left(x_{i}, t_{k-j}\right)\right]+o(\tau)
\end{aligned} ; 0<\alpha \leq 1
$$

Define this operator:

$$
L_{h, \tau}^{\alpha} u\left(x_{i}, t_{k+1}\right)=\frac{\tau^{-\alpha}}{\Gamma(2-\alpha)} \sum_{j=0}^{k}\left[u\left(x_{i}, t_{k-j+1}\right)-u\left(x_{i}, t_{k-j}\right)\right]
$$

Let $\mathrm{c}$ and $\mathrm{c}_{1}$ are two constants, then:

$$
\left|\frac{\partial^{\alpha} u\left(x_{i}, t_{k+1}\right)}{\partial t^{\alpha}}-L_{h, \tau}^{\alpha} u\left(x_{i}, t_{k+1}\right)\right| \leq c_{1} \tau \int_{0}^{t_{k+1}} \frac{d s}{\left(t k+1^{-s}\right)^{\alpha}} \leq c \tau
$$

Now, shifted Grünwald formula used to approximate Riemann-Liouville of order $1 \leq \beta \leq 2$ :

$$
\begin{aligned}
& \frac{\partial^{\beta} u(x, t)}{\partial x^{\beta}}=D_{x}^{\beta} u\left(x_{i}, t_{k+1}\right) \\
& =\frac{1}{h^{\beta}} \sum_{j=0}^{i+1} g_{j} u\left(x_{j}-(i-1) h, t_{k+1}\right)+O(\tau+h)
\end{aligned}
$$

Where for $\mathrm{i}=0,1,2, \ldots ; \quad 0<\beta \leq 2$

$$
g_{0}=1 ; g_{1}=-\beta ; g_{j}=(-1)^{j} \frac{\beta(\beta-1)(\beta-2) \ldots(\beta-j+1)}{j !}
$$

Put equations (9, 26 and 29) in equation (1), yield

$$
\begin{aligned}
& \frac{\tau^{-\alpha}}{\Gamma(2-\alpha)} \sum_{j=0}^{k} b_{j}\left(u_{i}^{k-j+1}-u_{i}^{k-j}\right)=\frac{1}{h^{\beta}} \sum_{j=0}^{i+1} g_{j} u_{i-j+1}^{k+1}+ \\
& \sum_{j=1}^{k} \frac{\tau}{2}\left(u_{i}^{k-j+1}-u_{i}^{k-j}\right)+q_{i}^{k-1}+o(\tau+h)
\end{aligned}
$$

Let $\omega=\tau^{\alpha} \Gamma(2-\alpha) ; r=\frac{\omega}{h^{\beta}} ; c=\frac{\tau \omega}{2}$ then:

$$
\begin{aligned}
& \left(u_{i}^{k+1}-u_{i}^{k}\right)-r \sum_{j=1}^{i+1} g_{j} u_{i-j+1}^{k+1}=\sum_{j=0}^{k} c\left(u_{i}^{k-j+1}-u_{i}^{k-j}\right)- \\
& \sum_{j=1}^{k} b_{j}\left(u_{i}^{k-j+1}-u_{i}^{k-j}\right)+q_{i}^{k-1}+o(\tau+h)
\end{aligned}
$$

$$
\begin{aligned}
(1+\beta r-c) u_{i}^{k+1}- & r \sum_{\substack{j=0 \\
j \neq 1}}^{i+1} g_{j} u_{i-j+1}^{k+1}=\left(1+b_{1}\right) u_{i}^{k}+\left(c+b_{k}\right) u_{i}^{0} \\
& +\sum_{j=1}^{k-1}\left(2 c+b_{j}-b_{j+1}\right) u_{i}^{k-1}+\omega q_{i}^{k+1}
\end{aligned}
$$


Where $\mathrm{i}=1,2, \ldots, \mathrm{m}-1 ; \mathrm{k}=1,2, \ldots, \mathrm{n}-1$ further, the system of equations( 33 ) written at $\mathrm{k}=0, \mathrm{k}=1$ and $\mathrm{k}>1$ respectively:

$$
(1+\beta r-c) u_{i}^{1}-r \sum_{\substack{j=0 \\ j \neq 1}}^{i+1} g_{j} u_{i-j+1}^{1}=(1+c) u_{i}^{0}+\omega q_{i}^{1}
$$

$$
\begin{gathered}
(1+\beta r-c) u_{i}^{2}-r \sum_{\substack{j=0 \\
j \neq 1}}^{i+1} g_{j} u_{i-j+1}^{2}=\left(1+2 c-b_{1}\right) u_{i}^{1}+ \\
\left(c+b_{1}\right) u_{i}^{0}+\omega q_{i}^{1}
\end{gathered}
$$

$$
\begin{aligned}
& (1+\beta r-c) u_{i}^{k+1}-r \sum_{\substack{j=0 \\
j \neq 1}}^{i+1} g_{j} u_{i-j+1}^{k+1}=\left(1+2 c-b_{1}\right) u_{i}^{k}+ \\
& \left(c+b_{k}\right) u_{i}^{0}+\omega q_{i}^{k+1}+\sum_{j=1}^{k-1}\left(2 c+b_{j}-b_{j+1}\right) u_{i}^{k-1}
\end{aligned}
$$

System of equations (34, 35 and 36) will be written by matrix formula as: $\mathrm{AU}^{\mathrm{k}+1}=\mathrm{U}^{\mathrm{k}}$

$$
\left\{\begin{array}{lc}
A U^{1}=(1+c) U^{0}+\omega G^{1} & k=0 \\
A U^{2}=\left(1+2 c-b_{1}\right) U^{1}+\left(c+b_{1}\right) U^{0}+\omega G^{2} & k=1 \\
A U^{k+1}=\left(1+2 c-b_{1}\right) U^{k}+\left(c+b_{k}\right) U^{0}+\omega G^{k+1}+ \\
\sum_{j=1}^{k=i}\left(2 c+b_{j}-b_{j+1}\right) U^{k+1} & k>2
\end{array}\right\}
$$

Where $A=\left[A_{i j}\right]$ is the matrix of coefficient, it has the form:

$$
A_{i j}=\left\{\begin{array}{ll}
-r & j=i+1 \\
1-c+\beta r & j=i \\
-r g_{2} & j=i-1 \\
-r g_{i-j+1} & j<i-1 \\
0 & \text { otherwise }
\end{array}\right\}
$$

$$
\left.\begin{array}{c}
U_{k}=\left[U_{1}^{k}, U_{2}^{k}, \ldots, U_{m-1}^{k}\right]^{T} ; \\
\text { Where } f=\left[f\left(x_{1}\right), f\left(x_{2}\right), f\left(x_{3}\right), \ldots, f\left(x_{m-1}\right)\right]^{T} \\
Q_{k}=\left[q_{1}^{k}, q_{2}^{k}, \ldots, q_{m-1}^{k}\right]^{T} ;
\end{array}\right\}
$$

\section{5-Stability and Convergence:}

There are three fundamental properties (consistency, convergence and stability), that every approximation of partial differential equations by finite differences, should possess it. The (Peter Lax theory), below, Will be shown the relation between these three properties.

\section{consistency}

implies that the finite difference equation is a good approximation of the partial differential equation,

\section{convergence}

implies that the solution of the difference equation approaches the solution of the partial differential equation as the computational mesh is refined.

\section{Stability}

implies that the solution of the difference equation is not too sensitive to small perturbations ( say, initial data), These properties are often difficult to verify for realistic problems, but they can be explained and illustrated quite easily using difference schemes for some simple model problems. Peter Lax, has made major contributions in areas including mathematical physics, in areas of numerical analysis. He gaves important theory, in this theory, to prove convergence one can work with the discrete scheme alone, providing it is consistent.

\section{5-1 Stability and Convergence of explicit finite differe-nce method, equation (19).}

Theorem1 (Lax Equivalence Theorem)

If the finite difference method $\mathrm{U}^{\mathrm{n}+1}=\mathrm{BU}^{\mathrm{n}}+\mathrm{kf}^{\mathrm{n}}$ is stable, then $\left\|U_{n}-u_{n}\right\| \leq \mathrm{CT} \max _{m=0, \cdots, n-1}\left\|T_{m}\right\|$ for all $\mathrm{n}$ such that

$\mathrm{nk}=\mathrm{T}$. Where:

1- $\mathrm{U}_{\mathrm{n}}, \mathrm{u}_{\mathrm{n}}$ denotes the vector of approximate and exact solutions $\left(x_{j}, t_{n}\right)$ at mesh points $\left(x_{j}, t_{n}\right)$ respectively, $\mathrm{T}_{\mathrm{m}}$ dented a vector of local truncation errors $\mathrm{T}\left(\mathrm{x}_{\mathrm{j}}, \mathrm{t}_{\mathrm{m}}\right)$.

2- So provided the method is consistent, the convergence rate is determined by how quickly the maximum over all local truncation errors (up to $t=$ T) approaches 0 as

$\mathrm{k} \rightarrow 0$. So "consistency + stability $=\Rightarrow$ convergence". For more detail of proof, see $[20,12]$.

\section{Theorem2 (Gerschgorin's Theorem):}

Let $A$ be a coefficients matrix $A=\left(a_{i j}\right)$, and let $x=\left(x_{1}\right.$ $\left.\mathrm{x}_{2}, \ldots, \mathrm{X}_{\mathrm{n}}\right)$, be an eigenvector of $\mathrm{A}$ corresponding to the Eigen value $\lambda$. Then for some $i$ we have $\left|x_{i}\right| \geq \mid$ $x_{j} \mid$ for all $j \neq i$, and since $x$ is an eigen-value, then

$\left|\mathrm{x}_{\mathrm{i}}\right| \geq 0$ and $\mathrm{Ax}=\lambda \mathrm{x}$ or $(\lambda \mathrm{I}-\mathrm{A}) \mathrm{x}=0$, Which represents $n$ simultaneous equations for the $i^{\text {th }}$ equation as:

$$
\left(\lambda-a_{i j}\right) x_{i}-\sum_{j \neq i} a_{i j} x_{j}=0 \text { Then } \lambda=a_{i i}-\sum_{j \neq i} a_{i j} \frac{x_{j}}{x_{i}}=0
$$

These eigenvalue lies in one circles $\left|\lambda-a_{i i}\right| \leq \sum_{j \neq i} a_{i j}$

This means there are $\mathrm{n}$ circles corresponding to $\mathrm{i}=1,2, \ldots, \mathrm{n}$.

Suppose that $B(r), 0 \leq r \leq 1$ is the (n by $n$ ) matrix given by $b_{i i}=a_{i i}$ then $b_{i j}=r a_{i j} ; i \neq j$ then eigenvalues of $\mathrm{b}(\mathrm{r})$ lie in the circles $\left|t-a_{i i}\right| \leq t \sum_{j \neq i}\left|a_{i j}\right|$. 
Since in this method a Grunewald formula is using to approximate Riemann fractional derivative and approximate Caputo fractional derivative, then the consistency proof for this case are facilitated by assuming zero Dirichlet boundary conditions, So that the solution may be zero-extended beyond the interval $0 \leq \mathrm{x} \leq \mathrm{L}$. thus the Riemann, Grünwald and Caputo definitions for the discratization have been shown to be $\mathrm{O}(\Delta \mathrm{x})$ for $1 \leq \beta \leq 2$ and $\mathrm{O}(\Delta \mathrm{t})$ for $0 \leq \alpha$ $\leq 1$. See [14-15-16].

In view of Lax's equivalence theorem these methods converge if and only if these are stable. Since the system ofequation of explicit written by the matrix form as: $U^{k+1}=A U^{k}+\omega F^{k}$ Where

$$
U_{k}=\left[u_{1}^{k}, u_{2}^{k}, \ldots \mu_{m-1}^{k}\right]^{T} ; \mathrm{F}^{\mathrm{k}}=\left[f_{0}^{k}, f_{1}^{k}, f_{2}^{k}, \ldots, f_{m-1}^{k}\right]^{T}
$$

and

$\mathrm{f}^{\mathrm{k}}=\mathrm{f}\left(\mathrm{x}, \mathrm{t}_{\mathrm{k}}, \mathrm{u}, \mathrm{g}\right)$ at $\mathrm{k}$ time step this mean the term of function add to the stander heatequation, $\mathrm{A}$ is the matrix of coefficients, and is the sum of a lower triangular matrix and super-diagonal matrix. The matrix entries $A_{i j}$ for $i=1,2, \ldots, m-1$; and $j=1,2, \ldots, m-$ 1,defined by :

$$
A= \begin{cases}0 & \text { if } j \geq i+2 \\ 1+g_{1} & \text { if } j=i \\ r g_{i-j+1} & \text { otherwise }\end{cases}
$$

While $A_{0,0}=1, A_{0, j}=0$ for $j=1,2, \ldots, m \quad A_{m, m}=1$ and $A_{m, j}=0$ for $j=0,1,2, \ldots, m-1$ with notes(a,b,c and $\left.d\right)$ at $(2-1)$, and by the Greschgorin theorem the eigenvalue of matrix $\mathrm{A}$ lie in the union of the circles centered at $\mathrm{A}_{\mathrm{ii}}$ with radius $\boldsymbol{R}_{i} \sum_{j \neq i} A_{i j}$ we have $\mathrm{A}_{\mathrm{ii}}$ $=1+\mathrm{r} \mathrm{g}_{1}=1-\mathrm{r} \beta$ and for $\mathrm{R}_{\mathrm{i}}$ we have: $R_{i}=\sum_{\substack{j=0 \\ j \neq i}}^{m} A_{i j}=\sum_{j=0}^{i+1} A_{i j}=r \sum_{\substack{j=0 \\ j \neq i}}^{m} g_{i j} \leq r \beta=1-A_{i i}$

Therefore $A_{i i}+R_{i} \leq 1$. We have Aii- $R_{i}=1-r \beta-R_{i}$ $\geq 1-2 \mathrm{r} \beta$. So that we have for spectral radius of the matrix $A$ to be at most one, it suffices to have (1$2 \mathrm{r} \beta) \geq-1$. which yields the following condition of $r$, $r=\frac{\tau^{\alpha}}{h^{\beta}} \leq \frac{1}{\beta}$.

Under this condition on $r$ the spectral radius of matrix A is bounded by one, with spectral radius so bounded, the numerical error do not grow, and the explicit method defined above is conditionally stable. Moreover the explicit method defined above is consistent with order $\mathrm{O}\left(\Delta \mathrm{t}^{\mathrm{n}}\right)+\mathrm{O}\left(\Delta \mathrm{h}^{\mathrm{m}}\right)$ ' where $\mathrm{n}, \mathrm{m}$ are integer numbers with $(n-1 \leq \alpha \leq n)$ and $(m-1 \leq \beta$ $\leq \mathrm{m}$ ). This mean explicit method consistent and conditionally stable then it is converging, the one of special case is;

if $\alpha=1$ and $\beta=2$ the condition become $r \leq 1 / 2$, this condition of classical parabolic of PDE.

\section{5-2 Stability and Convergence of implicit finite difference approximate equation (33):}

\section{5-2-1 Stability:}

the following lemma will be proved for the system of equations, which are using to approximate solution of eq(1) by using implicit way, the coefficients $b_{k}$ and $g_{j}$, where $(k=0,1,2, \ldots)$; $(j=1,2, \ldots)$ satisfy the following:

- $b_{j}>b_{j+1}$ for all $j=1,2, \ldots$

- $b_{0}=1 ; b_{j}>0$ for all $j=0,1,2, \ldots$

- $\quad \mathrm{g}_{1}=-\beta ; \mathrm{g}_{\mathrm{j}} \geq 0$ for all $\mathrm{j} \neq 1 ; \sum_{j=0}^{\infty} g_{j}=0$

- for any positive integer $\mathrm{n} ; \sum_{j=0}^{n} g_{j}<0$

Suppose that $\tilde{U}_{i}^{k} ; \mathrm{i}=0,1 \ldots \mathrm{m} ; \mathrm{k}=0,1, \ldots \mathrm{n} \quad$ is approximate solutions of equation (33). Define error as: $\tilde{\varepsilon}_{i}^{k}=\tilde{u}_{i}^{k}-u_{i}^{k}$ for all $\mathrm{i} ; \mathrm{k}$, the error satisfies system equations then:

$$
(1+\beta r-c) \varepsilon_{i}^{1}-r \sum_{\substack{j=0 \\ j \neq 1}}^{i+1} g_{j} \varepsilon_{i-j+1}^{1}=\left(2+3 c-b_{1}\right) \varepsilon_{i}^{0}
$$

$$
\begin{gathered}
(1+\beta r-c) \varepsilon_{i}^{k+1}-r \sum_{\substack{j=0 \\
j \neq 1}}^{i+1} g_{j} \varepsilon_{i-j+1}^{k+1}=\left(1+2 c-b_{1}\right) \varepsilon_{i}^{k}+ \\
+\left(c+b_{k}\right) \varepsilon_{i}^{0}+2 c \sum_{j=1}^{k-1} \varepsilon_{i}^{j}+\sum_{j=1}^{k-1}\left(b_{j}-b_{j+1}\right) \varepsilon_{i}^{k-1}
\end{gathered}
$$

Equations (33 and 34) written by using matrix form as:

$$
\left\{\begin{array}{l}
A E^{1}=\left(2+3 c-b_{1}\right) E^{0} \\
A E^{k+1}=\left(1+2 c-b_{1}\right) E^{k}+\left(c+b_{k}\right) E^{0}+ \\
2 c \sum_{j=1}^{k-i} E^{j}+\sum_{j=1}^{k-i}\left(b_{j}-b_{j+1}\right) E^{k-1}
\end{array}\right\}
$$

Where $E^{k}=\left[\varepsilon_{1}^{k}, \varepsilon_{2}^{k}, \ldots, \varepsilon_{m-1}^{k}\right]^{T}$;

Now we use mathematical induction to prove $\left\|E^{k}\right\|_{\infty} \leq\left\|E_{E} \mathrm{O}\right\|_{\infty}$ for all $\mathrm{k}=1,2, \ldots$, so that the theorem will be done then fractional implicit difference method defined in equation (33) is unconditionally stable.

Now when $k=1$ not that, and $g_{j}>0, j \neq 1$, then from equation (40 and 41)

$$
\begin{gathered}
(1+\beta r-c) \varepsilon_{i}^{1}-r \sum_{\substack{j=0 \\
j \neq 1}}^{i+1} g_{j} \varepsilon_{i-j+1}^{1}=\left(2+3 c-b_{1}\right) \varepsilon_{i}^{0} \\
M_{1} \varepsilon_{i}^{1}-M_{2} \sum_{\substack{j=0 \\
j \neq 1}}^{i+1} g_{j} \varepsilon_{i-j+1}^{1}=\left(2+3 c-b_{1}\right) \varepsilon_{i}^{0}
\end{gathered}
$$


Where $_{M_{1}}=\frac{(1+\beta r-c)}{\left(2+3 c-b_{1}\right)} ; M_{2}=\frac{r}{\left(2+3 c-b_{1}\right)} ;$

And since $\left(2-3 c-b_{1}\right)>0$.

$$
\begin{aligned}
& \text { Let }\left\|_{E^{1} \|_{\infty}}=\right\| \varepsilon_{i}^{1} \|_{\infty}=\underset{0<i<m-1}{\operatorname{MAX}\left|\varepsilon_{i}^{1}\right|} \\
& \begin{aligned}
\left\|E^{1}\right\|_{\infty}=\left\|\varepsilon_{i}^{1}\right\|_{\infty} \leq M_{1}\left|\varepsilon_{i}^{1}\right|-M_{2} \sum_{\substack{j=0 \\
j \neq 1}}^{i+1} g_{j}\left|\varepsilon_{i}^{1}\right| \\
\leq M_{1}\left|\varepsilon_{i}^{1}\right|-M_{2} \sum_{\substack{j=0 \\
j \neq 1}}^{i+1} g_{j}\left|\varepsilon_{i-j+1}^{1}\right| \\
\leq\left|M_{1} \varepsilon_{i}^{1}-M_{2} \sum_{\substack{j=0 \\
j \neq 1}}^{i+1} g_{j} \varepsilon_{i-j+1}^{1}\right|=\left\|\varepsilon_{i}^{1}\right\| \leq\left\|E^{O}\right\|_{\infty}
\end{aligned}
\end{aligned}
$$

So that we have $\left\|E^{1}\right\|_{\infty} \leq\left\|E^{\mathrm{O}}\right\|_{\infty}$, (true at $\left.\mathrm{k}=1\right)$.

assume that it is true for $\mathrm{k}=\mathrm{j}$, this mean: $\|E j\|_{\infty} \leq\|E \mathrm{O}\|_{\infty}$ for $\mathrm{j}=1,2, \ldots, \mathrm{k}$, now

for $\mathrm{k}+1$ we have, $\left\|E^{k+1}\right\|_{\infty} \leq\left\|\varepsilon_{i}^{k+1}\right\|_{\infty}=\underset{0<i<m-1}{\operatorname{MAX}}\left|\varepsilon_{i}^{k+1}\right|$

$$
\begin{aligned}
\left\|E^{k+1}\right\|_{\infty}=\left\|\varepsilon_{i}^{k+1}\right\|_{\infty} & \leq(1+\beta r-c)\left|\varepsilon_{i}^{k+1}\right|-r \sum_{\substack{j=0 \\
j \neq 1}}^{i+1} g_{j}\left|\varepsilon_{i}^{k+1}\right| \\
& \leq(1+\beta r-c)\left|\varepsilon_{i}^{k+1}\right|-r \sum_{\substack{j=0 \\
j \neq 1}}^{i+1} g_{j}\left|\varepsilon_{i-j+1}^{k+1}\right|
\end{aligned}
$$$$
\leq\left|(1+\beta r-c) \varepsilon_{i}^{k+1}-r \sum_{\substack{j=0 \\ j \neq 1}}^{i+1} g_{j} \varepsilon_{i}^{k+1}\right|
$$$$
=\left|\begin{array}{l}
\left(1+2 c-b_{1}\right) \varepsilon_{i}^{k}\left(c+b_{k}\right) \varepsilon_{i}^{0}+2 c \sum_{j=1}^{k-1} \varepsilon_{i}^{j} \\
+\sum_{j=1}^{k-1}\left(b_{j}-b_{j+1}\right) \varepsilon_{i}^{k-1}
\end{array}\right|
$$$$
\leq\left(1+2 c-b_{1}\right)\|E k\|_{\infty}\left(c+b_{k}\right)\|E \mathrm{O}\|_{\infty}+
$$$$
2 c \sum_{j=1}^{k-1}\|E j\|_{\infty}+\sum_{j=1}^{k-1}\left(b_{j}-b_{j+1}\right)\left\|E^{k-1}\right\|_{\infty}
$$$$
\leq\left(1+2 c-b_{1}\right)\left\|E^{\mathrm{O}}\right\|_{\infty}\left(c+b_{k}\right)\left\|E^{\mathrm{O}}\right\|_{\infty}+
$$$$
2 c \sum_{j=1}^{k-1}\|E \mathrm{O}\|_{\infty}+\sum_{j=1}^{k-1}\left(b_{j}-b_{j+1}\right)\|E \mathrm{O}\|_{\infty}
$$$$
=\left\|E^{\mathrm{O}}\right\|_{\infty} \text { so } \text { that }\left\|E^{k+1}\right\|_{\infty} \leq\left\|E^{\mathrm{O}}\right\|_{\infty}
$$

\section{5-2-2Convergence:}

Let $\mathrm{U}^{\mathrm{k}}$ be the numerical solution of equation (33) at mesh-points $\left(x_{i}, t_{k}\right)$, where $i=1,2, \ldots, m ; k=1,2, \ldots, n$, now, define error as:

$\mathrm{e}^{\mathrm{k}}=\mathrm{u}\left(\mathrm{x}_{\mathrm{i}}, \mathrm{t}_{\mathrm{k}}\right)-\mathrm{U}_{\mathrm{i}}^{\mathrm{k}} \quad$ for all $\mathrm{i}$ and $\mathrm{k}$.

sincee $^{\mathrm{k}}=\left(\mathrm{e}^{\mathrm{k}}{ }_{1}, \mathrm{e}^{\mathrm{k}}, \ldots, \mathrm{e}_{\mathrm{m}-1}^{\mathrm{k}}\right)^{\mathrm{T}}$,
Madeha .S/Ahmed .M/Eman .H/Raghad .K

substitution $\mathrm{e}^{\mathrm{k}}$ and $\mathrm{e}^{0}$ into equation (41) we have:

$$
\begin{aligned}
& (1+\beta r-c) e_{i}^{1}-r \sum_{\substack{j=0 \\
j \neq 1}}^{i+1} g_{j} e_{i-j+1}^{1}=\left(2+3 c-b_{1}\right) e_{i}^{0} \\
& M_{1} e_{i}^{1}-M_{2} \sum_{\substack{j=0 \\
j \neq 1}}^{i+1} g_{j} e_{i-j+1}^{1}=e_{i}^{0}=R_{i}^{1} \\
& (1+\beta r-c) e_{i}^{k+1}-r \sum_{\substack{j=0 \\
j \neq 1}}^{i+1} g_{j} e_{i-j+1}^{k+1}=\left(1+2 c-b_{1}\right) e_{i}^{k} \\
& \left(c+b_{k}\right) e_{i}^{0}+2 c \sum_{j=1}^{k-1} e_{i}^{j}+\sum_{j=1}^{k-1}\left(b_{j}-b_{j+1}\right) e_{i}^{k-1}+R_{i}^{k+1}
\end{aligned}
$$

We have $(\mathrm{i}=1,2, \ldots, \mathrm{m}-1 ; \mathrm{k}=1,2, \ldots, \mathrm{n})$ and $\left|R_{1}^{k}\right| \leq C\left(\tau^{2+\alpha}+\tau^{\alpha} h\right)$

Then, using of the mathematical induction to give the convergence analysis as follows:

$$
\begin{aligned}
& \text { for } \mathrm{k}=1,\left\|e^{1}\right\|_{\infty}=\left\|e_{t}^{1}\right\|_{\infty}=\underset{0<i<m-1}{\operatorname{MAX}}\left|e_{i}^{1}\right| \text { Then } \\
& \begin{aligned}
\left\|e^{1}\right\|_{\infty} \leq M_{1}\left|e_{i}^{1}\right|-M_{2} \sum_{\substack{j=0 \\
j \neq 1}}^{i+1} g_{j}\left|e_{i}^{1}\right| \\
\leq M_{1}\left|e_{i}^{1}\right|-M_{2} \sum_{\substack{j=0 \\
j \neq 1}}^{i+1} g_{j}\left|e_{i-j+1}^{1}\right| \\
\leq\left|M_{1} e_{i}^{1}-M_{2} \sum_{\substack{j=0 \\
j \neq 1}}^{i+1} g_{j} e_{i-j+1}^{1}\right|=\left|e_{i}^{o}+R_{i}^{k}\right|
\end{aligned}
\end{aligned}
$$

Since $\mathrm{e}^{0}=0$ and $\left|R_{1}^{k}\right| \leq C\left(\tau^{2+\alpha}+\tau^{\alpha} h\right)$

So $\left\|e^{1}\right\|_{\infty} \leq C\left(\tau^{2+\alpha}+\tau^{\alpha} h\right)$

Suppose that $\|e j\|_{\infty} \leq C b_{j-1}^{-1}\left(\tau^{2+\alpha}+\tau^{\alpha} h\right)$

For $\mathrm{j}=1,2, \ldots, \mathrm{k}$, we prove that true for $\mathrm{k}+1$

$$
\text { Let }\left\|e_{i}^{k+1}\right\|_{\infty}=\underset{0<i<m-1}{\operatorname{MAX}}\left|e_{i}^{k+1}\right|
$$

Not $b_{j}^{-1} \leq b_{k}^{-1} ; j=0,1, \ldots, k$

$$
\begin{aligned}
\left|e_{i}^{k+1}\right|_{\infty} & \leq(1+\beta r-c)\left|e_{i}^{k+1}\right|-r \sum_{\substack{j=0 \\
j \neq 1}}^{i+1} g_{j}\left|e_{i}^{k+1}\right| \\
& \leq(1+\beta r-c)\left|e_{i}^{k+1}\right|-r \sum_{\substack{j=0 \\
j \neq 1}}^{i+1} g_{j}\left|e_{i-j+1}^{k+1}\right| \\
& \leq\left|(1+\beta r-c) e_{i}^{k+1}-r \sum_{\substack{j=0 \\
j \neq 1}}^{i+1} g_{j} e_{i}^{k+1}\right|
\end{aligned}
$$




$$
\begin{aligned}
& \left|\begin{array}{l}
\left(1+2 c-b_{1}\right) e_{i}^{k}\left(c+b_{k}\right) e_{i}^{\mathrm{O}}+2 c \sum_{j=1}^{k-1} e_{i}^{j} \\
+\sum_{j=1}^{k-1}\left(b_{j}-b_{j+1}\right) e_{i}^{k-1}+R_{i}^{k+1}
\end{array}\right| \\
& \leq\left(1+2 c-b_{1}\right) \| e^{k\left\|_{\infty}+\left(c+b_{k}\right)\right\| e^{\mathrm{O}} \|_{\infty}+} \\
& \quad+2 c \sum_{j=1}^{k-1}\left\|e^{j}\right\|_{\infty}+\sum_{j=1}^{k-1}\left(b_{j}-b_{j+1}\right)\left\|e^{k-1}\right\|_{\infty}+\left|R_{i}^{k+1}\right|
\end{aligned}
$$

Since $\|e j\|_{\infty} \leq C b_{j-1}^{-1}\left(\tau^{2+\alpha}+\tau^{\alpha} h\right) ;$ and $\|e j\|_{\infty}=0$

$$
\begin{aligned}
\leq & {\left[\left(1+2 c-b_{1}\right) b_{j-1}^{-1}+2 c \sum_{j=1}^{k-1} b_{k-j-1}^{-1}+\sum_{j=1}^{k-1}\left(b_{j}-b_{j+1}\right) b_{k-j-1}^{-1}\right] } \\
& C\left(\tau^{1+\alpha}+\tau^{\alpha} h\right)+\left|R_{1}^{k+1}\right|
\end{aligned}
$$

Using $b_{j}^{-1} \leq b_{k}^{-1}$ for $\mathrm{j}=0,1, \ldots, \mathrm{k}$ and $\left|R_{1}^{k}\right| \leq C\left(\tau^{1+\alpha}+\tau^{\alpha} h\right)$

$\leq\left[\left(1+2 c-b_{1}\right) b_{k}^{-1}+2 c \sum_{j=1}^{k-1} b_{k}^{-1}+\sum_{j=1}^{k-1}\left(b_{j}-b_{j+1}\right) b_{k}^{-1}\right]$

$C\left(\tau^{1+\alpha}+\tau^{\alpha} h\right)+C\left(\tau^{1+\alpha}+\tau^{\alpha} h\right)$

$\left\{b_{k}^{-1}\left[\left(1+2 c-b_{1}\right) b_{k}^{-1}+2 c \sum_{j=1}^{k-1} b_{k}^{-1}+\sum_{j=1}^{k-1}\left(b_{j}-b_{j+1}\right) b_{k}^{-1}\right]+1\right\}$

$C\left(\tau^{1+\alpha}+\tau^{\alpha} h\right)$

$b_{k}^{-1} C\left(\tau^{1+\alpha}+\tau^{\alpha} h\right)\left[\left(1+2 c-b_{1}\right)+\left(2 c(k-1) \sum_{j=1}^{k-1}\left(b_{j}-b_{j+1}\right)+b^{k}\right]\right.$

so that $\left\|e^{k+1}\right\|_{\infty} \leq C b_{k}^{-1}\left(\tau^{1+\alpha}+\tau^{1} h\right)$ fork $=0,1, \ldots$

Hence there is constant $\mathrm{C}$ such that:

$\left\|e^{k+1}\right\|_{\infty} \leq C b_{k}^{-1}\left(\tau^{1+\alpha}+\tau^{1} h\right)$ for $\mathrm{k}=0,1,2, \ldots$

If $\mathrm{k} \tau \leq \mathrm{T}$ is finite the convergence is given by the following theorem:

Theorem3: let $U^{k}{ }_{i}$ be approximate value of $u\left(x_{i}, t_{k}\right)$ computed by using equation (33), then there is a positive constant $\mathrm{C}$ such that:

$$
\left|U_{i}^{k}-u\left(x_{i}, t_{k}\right)\right| \leq C(\tau+h) ; i=1,2, \ldots, m-1 ; k=1,2, \ldots, n
$$

\section{6- Numerical Examples:}

Three examples with known exact solutions are considered. The examples are chosen such that the behavior of the solution has different characterizations with space and time ranging from polynomial, sinusoidal and exponentially decay.

Example 1: consider equation (1), with

$$
\begin{aligned}
q(x, t)= & \left(x^{2}-x^{3}\right)\left(\sin \left(t-\frac{\alpha}{4}\right)\right)-(\sin (t)+1)\left(\frac{\Gamma(3) x^{2-\beta}}{\Gamma(3-\beta)}\right. \\
& \left.-\frac{\Gamma(4) x^{3-\beta}}{\Gamma(4-\beta)}\right)-\Gamma(2.6275)\left(x^{2}-x^{3}\right)
\end{aligned}
$$

the boundary conditions $\mathrm{u}(0, \mathrm{t})=\mathrm{u}(1, \mathrm{t})=0, \mathrm{t}>0$; and the initial condition $(\mathrm{x}, 0)=\left(\mathrm{x}^{2}-\mathrm{x}^{3}\right), \mathrm{x} \in[0,1]$, where the exact solution is $\mathrm{u}(\mathrm{x}, \mathrm{t})=\left(\mathrm{x}^{2}-\mathrm{x}^{3}\right)$

$(\sin (\mathrm{t})+1)$

Table 1 shows different choice of $\mathrm{n}, \mathrm{m}, \alpha$ and $\beta$, for two methods.

\begin{tabular}{|l|l|l|l|l|l|l|l|l|}
\hline cha & $\alpha$ & $\beta$ & $\mathrm{n}$ & $\mathrm{m}$ & $\tau 1$ & $\tau 2$ & err1 & err2 \\
\hline 1 & .8 & 1.3 & $10^{\wedge} 4$ & $\mathbf{1 0}$ & .0001 & .0007 & .018 & .013 \\
\hline 2 & .5 & 1.5 & 50 & 50 & .2 & .06 & .01 & .0038 \\
\hline 3 & .8 & 1.3 & 50 & 20 & .2 & .05 & .01 & .0038 \\
\hline
\end{tabular}

Table 1

Figure1 illustrates the exact solution and the numerical solutions obtained by using explicit method table 1 shone the choice of $n, m$ to achieve condition of stability, the large step of time gives cmall mavimum arrer writh fived $n R$

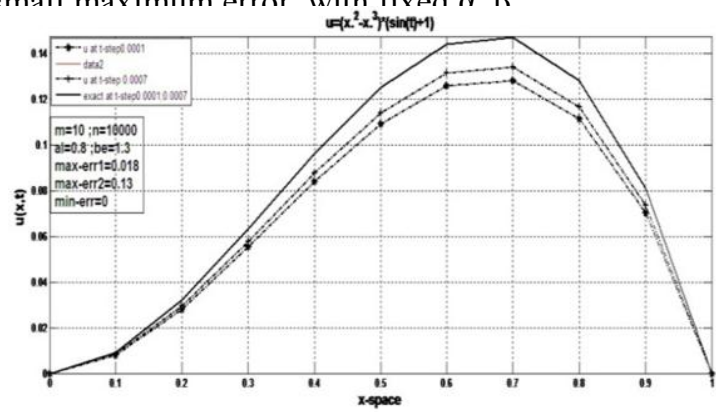

Figure1. numerical and anlaytic graph of soluthins using explicit method of examble 1

Figure (2) illustrates the exact and the numerical solution by using implicit method, for $\alpha=$ and $\beta=$ at two time-steps with different choice of (h. $\tau$ ).

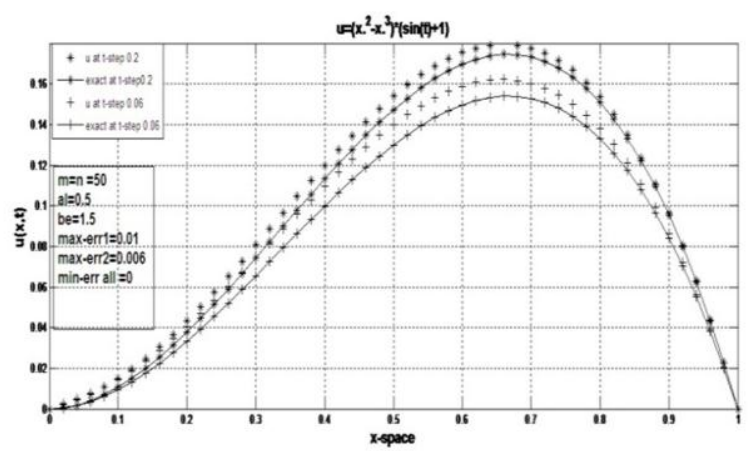

Figure2. numerical and anlaytic graph of soluthins using implicit method of examble 1

Figure (3)illustrates the exact and the numerical solution by using implicit method, for $\alpha=$ and $\beta=$ at two time-steps with different choice of $(h, \tau)$, 


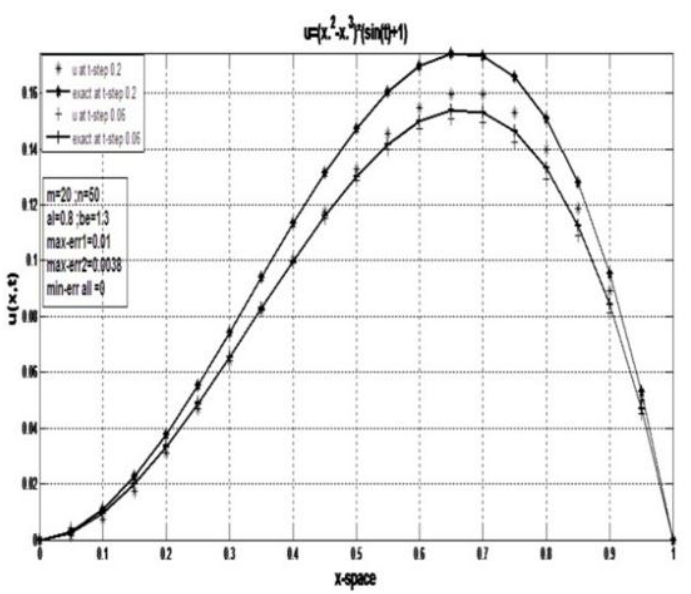

Figure3. numerical and anlaytic graph of soluthiı using implicit method of examble 1.

Example 2: consider equation (1), with

$$
\begin{aligned}
q(x, t)= & \left(e^{-t}\right)\left[\left(x^{4}-x^{3}\right)-\left(\frac{\Gamma(4) x^{4-\beta}}{\Gamma(3-\beta)}-\frac{\Gamma(5) x^{3-\beta}}{\Gamma(4-\beta)}\right)\right] \\
& -(\Gamma(3)-\Gamma(2.54))\left(x^{4}-x^{3}\right)
\end{aligned}
$$

the boundary conditions $\mathrm{u}(0, \mathrm{t})=\mathrm{u}(1, \mathrm{t})=0, \mathrm{t}>0$; and the initial condition $\mathrm{u}(\mathrm{x}, 0)=\left(\mathrm{x}^{4}-\mathrm{x}^{3}\right), \mathrm{x} \in[0,1]$, whose exact solution has the form $u(x, t)=\left(x^{4}-x^{3}\right)$ $(\exp (-t))$

Table 2 shone different choice of $\mathrm{n}, \mathrm{m}, \alpha$ and $\beta$, for two methods.

\begin{tabular}{|l|l|l|l|l|l|l|l|l|}
\hline cha & $\alpha$ & $\beta$ & $\mathrm{n}$ & $\mathrm{m}$ & $\tau 1$ & $\tau 2$ & err1 & err2 \\
\hline 4 & .5 & 1.5 & $\mathbf{1 6 e 4}$ & $\mathbf{2 0}$ & St_2 & St_9 & .026 & .0098 \\
\hline 5 & .5 & 1.5 & $\mathbf{2 5 0 0}$ & $\mathbf{5 0}$ & St_2 & St_9 & .007 & .005 \\
\hline 6 & .5 & 1.5 & $\mathbf{4 0}$ & 100 & .01 & .02 & .027 & .004 \\
\hline
\end{tabular}

Table 2

Figure4 shows the exact and approximate solutions using explicit method; goes to exact solution with high time step, different in error with different choice of $\tau$ at table 2 shone that.

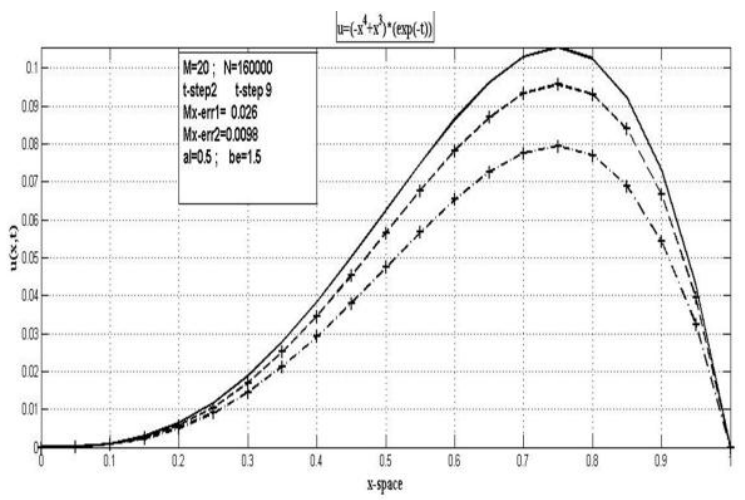

Figure4. numerical and anlaytic graph of soluthins using explicit method of examble 2
Figure5 and 6 show exact and approximate solutions by using implicit method, with different values of $\alpha$ and $\beta$. Both are choosing to show how the approximate solution go to exact solution with large values of $n$ and $m$.

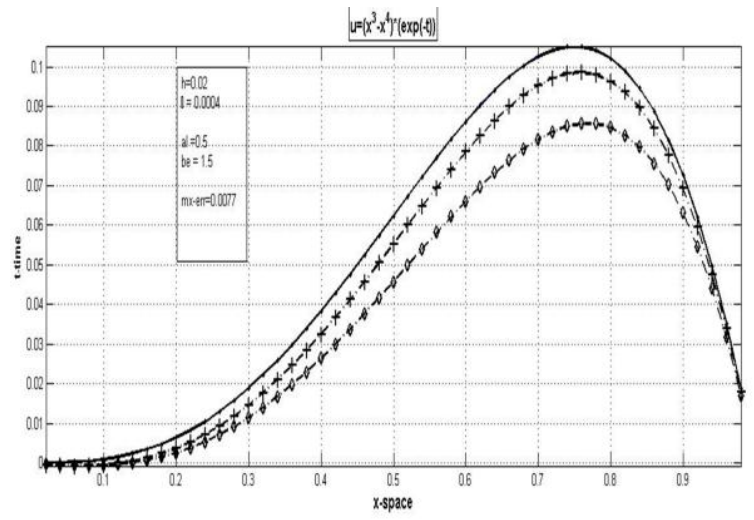

Figure5. numerical and anlaytic graph of soluthins using implicit method of examble 2

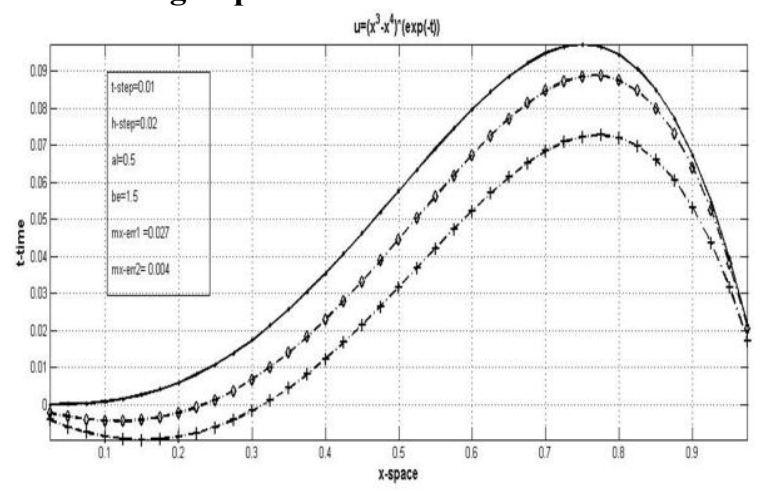

Figure6. numerical and anlaytic graph of soluthins using implicit method of examble 2

Example 3: consider equation (1), where

$$
\begin{aligned}
\mathrm{q}(\mathrm{x}, \mathrm{t}) & =\left(\mathrm{e}^{-\mathrm{t}}\right)\left[\sin (\pi \mathrm{x})-\left(\pi^{\beta} \sin \left(\pi x+\frac{\pi \beta}{4}\right)\right]\right. \\
& -(\Gamma(3)-\Gamma(2.54)) \sin (\pi x)
\end{aligned}
$$

With boundary and initial conditions: $u(0, t)=u(1, t)=0$; $\mathrm{t} \in[0,1] ; \mathrm{u}(\mathrm{x}, 0)=\sin (\pi \mathrm{x}), \mathrm{x} \in[0,1]$; with the exact solution $\mathrm{u}(\mathrm{x}, \mathrm{t})=\sin (\pi \mathrm{x})(\exp (-\mathrm{t}))$,

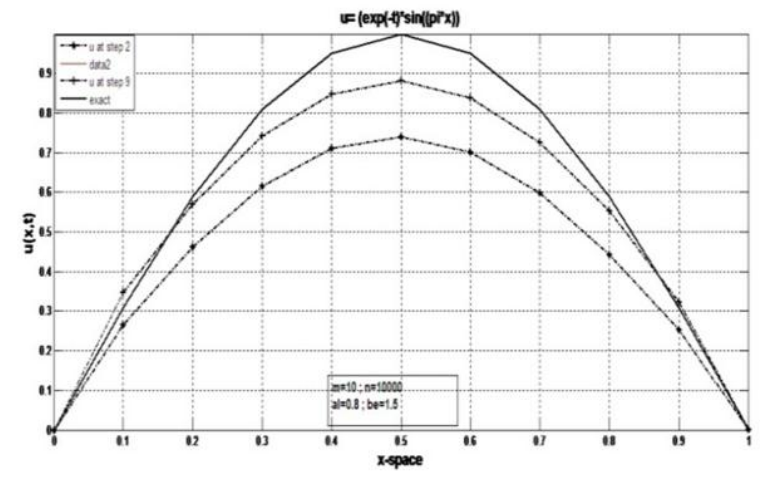

Figure7. numerical and anlaytic graph of soluthins using explicit method of examble 3 
Figure7 shows how the approximate solution goes to the exact solution with choose the higher time step, with fixed $(\alpha=0.8, \beta=1.5)$ and choose $(\mathrm{n}=$ $10^{\wedge} 4 ; \mathrm{m}=10$ ) to achieve the condition of stability.

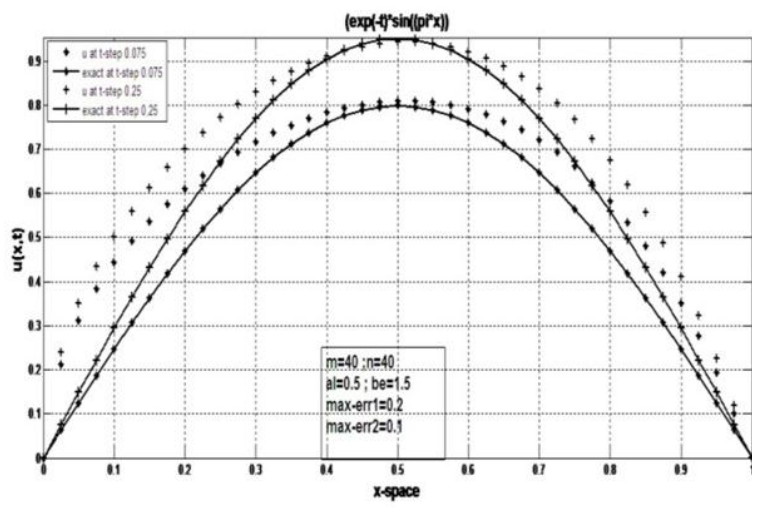

Figure8. numerical and anlaytic graph of soluthins using implicit method of examble 3

Figure 8 shows how the maximum error become small with high time step $(\tau=0.075 ; \tau=0.25)$, with fixed $(\alpha=0.5, \beta=1.5)$ and choose $(n=m=40)$.

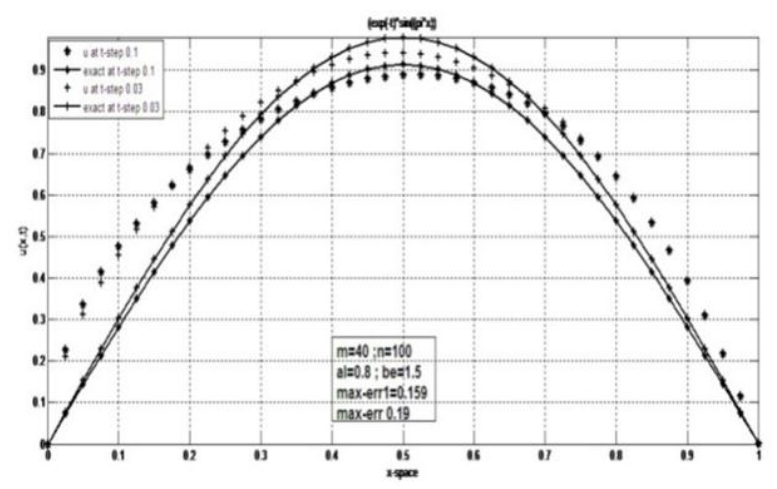

Figure9. numerical and anlaytic graph of soluthins using implicit method of examble 3

Figure 9 shows how the maximum error become small with high time step $(\tau=0.075 ; \tau=0.25)$, and with large choice of $(\mathrm{n}=100 ; \mathrm{m}=40)$, fixed $(\alpha=$ $0.5, \beta=1.5)$.

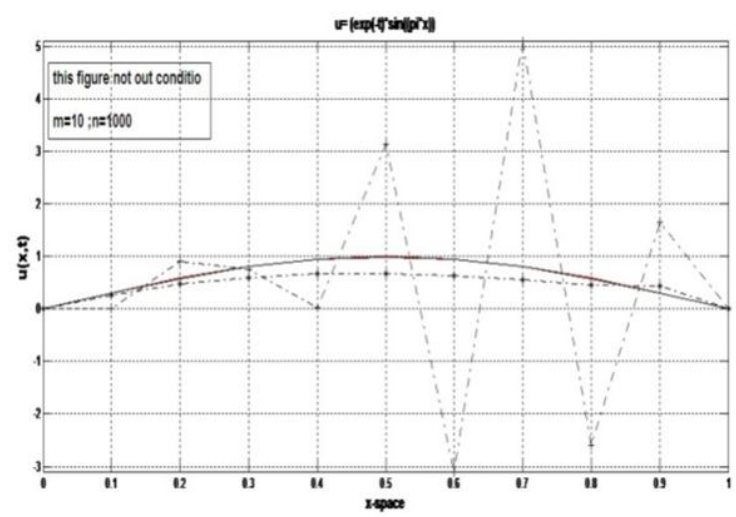

Figure10. where $(m, n)$ are not satisfy condation
Figure 10 shows what happen to approximate solution with chosen values of $n$, m that didn't achieve the condition of stability.

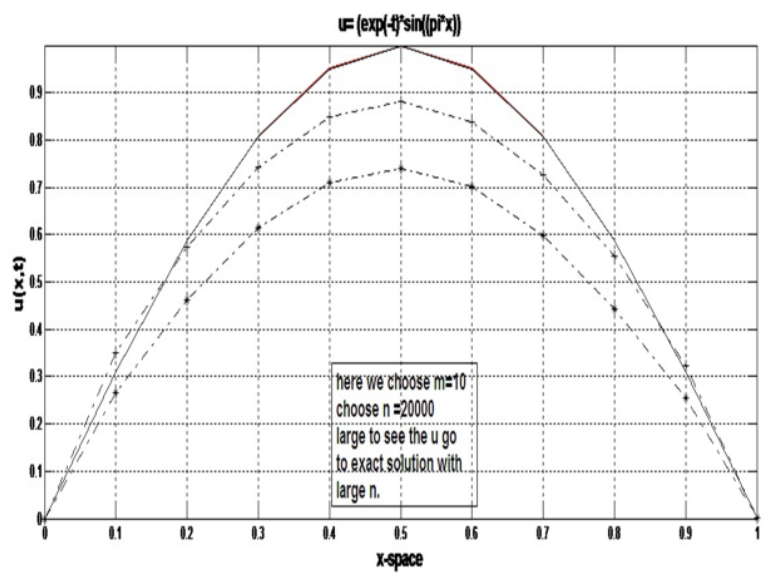

Figure11. where (m,n) are satisfy condation

Figure 11 shows that good approximation with chosen large $n, m$ with fixed $n$ and $m$ achieved condition of stability and fixed $\alpha$ and $\beta$.

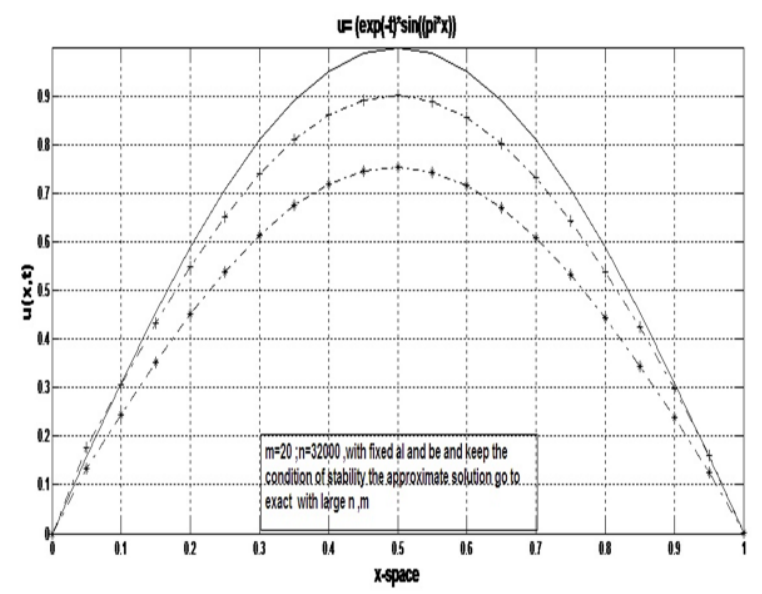

Figure12. shown the same example with choice n,m large

Figure 12 shows the choice of $n=20, m=32000$ the condition of stability is done and with fixed $\alpha$ and $\beta$ good approximation with chosen large $n, m$. 


\section{Conclusion}

in this work implicit method gives approximate solution better than explicit with the same time and space split periods i.e same choice of $(m, n)$. see Figure (1-9). Morever implicit method is unconditionlly stability and it's faster than explicit method because it isn't need high value of $m$ or $n$ to give small error. The explicit method has stability with this condition $r=\frac{\tau^{\alpha}}{h^{\beta}} \leq \frac{1}{\beta}$, this mean if we choose $\mathrm{m}$ integer number (i.e choose $\mathrm{h}=1 / \mathrm{m}$ ) then we must choose $n$ (i.e $\tau=1 / n$ ) tosatisfy this quality, see Figure10 where $(\mathrm{m}, \mathrm{n}$ are not satisfy condation ),Figure11 shows the same examble but with n,m to satisfy condation ,Figure 12 shows the same example with choice n,m larger than Figure 10,11.The adding of any terms, like the integral term, will don't give any changing in stability and converg, because, (since we use the method of trapezoidal to approximate integral term and it has error smaller than the order error of exiplicit or implicit methods, with this not: exiplicit method don't change in condition of stibilety).

\section{References:}

[1] A. F. yuwen, advanced heat and mass transfer, (2017).

[2] M. Caputo, F. Mainardi, Linear models of dissipation in an elastic solids, Riv. NuovoCimento, 161198,(1971).

[3] Stewart A. Silling, solitary waves in a peridynamic elastic solid,(2016).

[4] V. Bhambhani, "optimal fractional order proportional and integral controller for processes with random time delays", Utah State University, Logan, $\operatorname{Utah}(2008)$.

[5]A.M. Wazwaz "Partial Differential Equations andSolitary Waves Theory" Department of Mathematics Saint Xavier University.

[6] M.M. Meerschaert, C. Tadjeran, Finite difference approximations for fractional-dispersition flow equations, J. Comput. Appl. Math 172, p65-77,(2004).

[7] R. Gorenflo, F. Mainardi, " fractional calculus" integral and differential equations of fractional order.(2008).

[8] J.P. Roop, Computational aspects of FEM approximation of fractional advection dispersion equation on bounded domains in R2, J. Comp. Appl. Math,193, pp243-268,(2006).

[9] R.K. Rektorys, "The method of discretization in time andpartial differential equations".
[10] Z. Li, Z. Liang, Y. Yan, high-order numerical methods for solving time fractional partial differential equations, J Sci Comput DOI 10.1007/s10915-016-0319-1, (2017).

[11] P. Zhuang and F. Liu, Implicit difference approximation for the time fractional diffusion equation,87-99,(2006).

[12]S. Shen, F. Liu,Error analysis of an explicit finite difference approximation for the space fractional diffusion equation with insulated ends,pp, C871C887,(2005).

[13] M. Meerschaert, C. Tadjeran, Finite deference approximations for fractional advection-dispersion flow equations, J. Comput. Appl. Math, 172,6577,(2004).

[14] F. Mainardi,Yu, Luchko and G.Pagnini, The fundamental solution of the space-time fractional diffusion, Fractional Calculus and Applied Analysis, Vol. 4, No 2, pp. 153-192,(2001).

[15] R.Gorenflo,F. Manardi, D. Moretti and P.Paradisi,Time fractional Diffusion: A Discrete Random Walk Approach [J], Nonlinear Dynamics, 129-143,(2002).

[16] Diego A. Murio, Implicit finite difference approximation for time fractional diffusion equations, Computers and Mathematics with Applications,1138-1145,(2008).[15] FAWAQ Liu, M. M. Meerschaert, "Fractional Differential Equations".

[17] K.S. Miller and B. Ross, An Introduction to the Fractional Calculus and Fractional Deferential Equations, John Wiley, New York, 1993,

[18] F. Liu, S. Shen, V. Anh, I. Turner, Analysis of a discrete non-Markovian random walk approximation for the time fractional diffusion equation, ANZIAM J. 46,pp, C488-C504, (2005).

[19] M.M. Meerschaert, J. Mortensen, H.P, Scheffler, Vector Grünwald formula for fractional derivatives, Fract. Calc.Appl,7, pp 61-81,(2004).

[20] Tan Bui-Thanh, Equivalence Theorems and Their Application “ Sipt 13, (2010). 


\title{
تعميم طريقة الفروق المنتهية لحل معادلات تفاضلية جزئية معينة ذات رتب كسورية نوع القطع المكافيء
}

\author{
مديحة شتلتاغ يوسف احمد محمد شكر أيمان حسن عودة رغد كاظم صالح \\ الجامعة التكنولوجية_قسم العلوم التطبيقية_فرع الرياضيات وتطبيقات الحاسوب إنمان
}

: المستخلص : (1)

تم در اسة معادلات تفاضلية جزئية ذات رتب كسورية في الزمن و المكان معا. (S-TFDE)

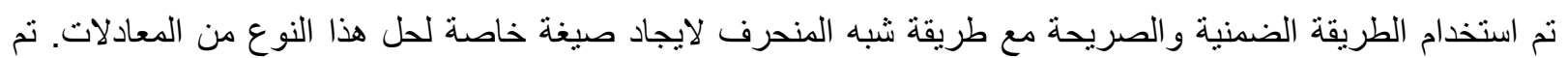

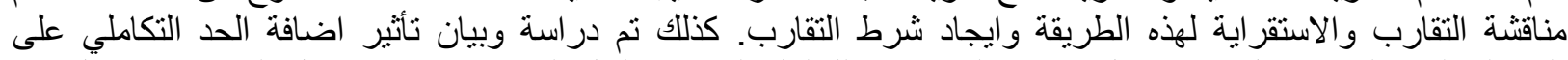

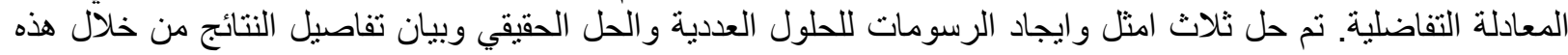

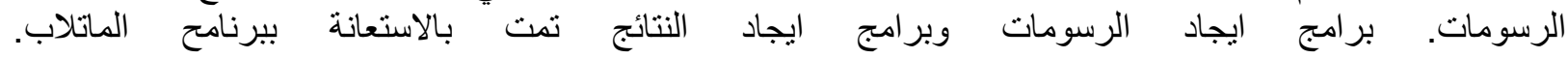

الرتب الكسورية. الكمات المفتبة: كسورية ، معادلات تفاضلية-تكاملية ذات رتب كسو، معادلات التفاضلية نوع القطع المكافيء ذات 